\title{
Optimization of Xenon Biosensors for Detection of Protein Interactions
}

Thomas J. Lowery, ${ }^{[a]}$ Sandra Garcia, ${ }^{[b]}$ Lana Chavez, ${ }^{[b]}$ E. Janette Ruiz, ${ }^{[b]}$ Tom Wu, ${ }^{[c]}$ Thierry Brotin, ${ }^{[d]}$ Jean-Pierre Dutasta, ${ }^{[d]}$ David S. King, ${ }^{[\mathrm{e}]}$ Peter G. Schultz, ${ }^{[\mathrm{c}]}$ Alex Pines, ${ }^{[\mathrm{b}]}$ David E. Wemmer. ${ }^{[a] *}$

[a] T. J. Lowery, Prof. D. E. Wemmer

Department of Chemistry

University of California at Berkeley

Berkeley, CA 94720 (USA)

and

Physical Biosciences Division

Lawrence Berkeley National Laboratory

1 Cyclotron Road, Berkeley, CA 94720 (USA)

[b] S. Garcia, L. Chavez, E. J. Ruiz, Prof. A. Pines

Department of Chemistry

University of California at Berkeley

Berkeley, CA 94720 (USA)

and

Material Sciences Division

Lawrence Berkeley National Laboratory

1 Cyclotron Road, Berkeley, CA 94720 (USA)

[c] T. Wu, Prof. P. G. Schultz

Department of Chemistry and The Skaggs Institute for

Chemical Biology

The Scripps Research Institute

10550 North Torrey Pines Road

La Jolla, California 92037 (USA)

[d] Dr. T. Brotin, Dr. J. P. Dutasta

Laboratoire de Chimie de l'ENS-Lyon (UMR 5182 CNRS/ENS-Lyon)

46 Allee d'Italie

69364 Lyon 07, France

[e] Dr. D. S. King

Department of Molecular and Cell Biology and

Howard Hughes Medical Institute

University of California at Berkeley

Berkeley, CA 94720 (USA) 


\section{Abstract}

Hyperpolarized ${ }^{129} \mathrm{Xe}$ NMR can detect the presence of specific lowconcentration biomolecular analytes by means of the xenon biosensor, which consists of a water-soluble, targeted cryptophane-A cage that encapsulates xenon. In this work we use the prototypical biotinylated xenon biosensor to determine the relationship between the molecular composition of the xenon biosensor and the characteristics of protein-bound resonances. The effects of diastereomer overlap, dipole-dipole coupling, chemical shift anisotropy, xenon exchange, and biosensor conformational exchange on protein-bound biosensor signal were assessed. It was found that optimal protein-bound biosensor signal can be obtained by minimizing the number of biosensor diastereomers and using a flexible linker of appropriate length. Both the linewidth and sensitivity of chemical shift to protein binding of the xenon biosensor were found to be inversely proportional to linker length.

\section{Keywords}

Biosensors, Hyperpolarized Xenon, Imaging Agents, Nuclear Magnetic Resonance, Avidin-biotin binding 


\section{Introduction}

Recent advances in nanomaterials and magnetic resonance polarization techniques have led to the development of new types of magnetic resonance imaging (MRI) contrast agents that provide for greater sensitivity and higher selectivity. Proton relaxation agents have been biochemically targeted to yield imaging signals that report the presence of specific molecules. Examples include detecting and imaging biomolecular binding events and enzyme activity with functionalized magnetite nanoparticles ${ }^{[1]}$ and imaging gene expression with chemically modified paramagnetic ions. ${ }^{[2]}$ Polarization-enhanced contrast agents have also been used to obtain extraordinary definition of perfused blood and tissue volumes. Dynamic nuclear polarization enhanced glucose has been used for angiography, ${ }^{[3]}$ and polarized helium and xenon for lung and tissue imaging. [4] Polarized nuclei offer high sensitivity, low-background, and relatively long relaxation times.

Unlike proton relaxation agents, which have been conjugated to target specific tissue types or biomolecules for achieving selective contrast, polarized nuclei have thus far only been used in a non-specific manner in which signal localization relies on slow transport and tissue barriers. One means of targeting polarized nuclei to a specific analyte or sample 
region uses a molecular adaptor, termed a xenon biosensor. This sensor was developed as a means to "functionalize" polarized xenon in aqueous solutions and target it to report on a specific biomolecular target or event. The prototypical xenon biosensor consists of three parts, a xenon-binding cryptophane-A cage, a short peptide for water solubility, and a moiety that binds a specific biomolecule. A biotinylated sensor was used to demonstrate that the biosensor-bound xenon resonances significantly broaden and shift downfield in the presence of avidin. ${ }^{[5-6]}$ The sensitivity of biosensor-encapsulated xenon to its local environment indicates that "functionalized" xenon can serve as a magnetic resonance reporter for targeted in situ biosensing and imaging. ${ }^{[7]}$

Our initial biotinylated cryptophane-A construct (Scheme 1, 1) gave rise to four narrow ${ }^{129} \mathrm{Xe}$ resonances when free in solution. These four resonances derive from the four diastereomers RLL, RLR, LLL, and LLR that arise from the chirality of the three biosensor components, the cage, peptide, and maleimide. ${ }^{[6]}$ In the absence of protein, two of the diastereomer resonances almost completely overlap with the other two, yielding two slightly separated peaks of $20 \mathrm{~Hz}$ total linewidth. ${ }^{[6]}$ The avidin-bound form of 1 yielded a single broad peak $\sim 200 \mathrm{~Hz}$ in linewidth that was shifted $\sim 2$ ppm downfield 
(Figure S1). The broadening observed upon binding appears to arise from an increase in correlation time through a combination of relaxation mechanisms. ${ }^{[6]}$

We envision applications of functionalized xenon to include spatially localized sensing of specific molecules (e.g. metabolites, antigens, etc.) in a selective and low-background manner by tethering a xenon binding cage to a selective affinity tag, such as an antibody, or a small molecule sensor, such as a ligand binding protein. ${ }^{[6,7]}$ Such applications require acquiring signal from biomolecule-bound xenon biosensor. The large linewidth observed for the protein-bound prototype sensor would significantly limit detection sensitivity. To address this issue we have prepared and determined NMR characteristics of six different biotinylated xenon biosensors when bound to avidin. Through these studies we identify the molecular features that impart optimal linewidth and sensitivity to biosensor applications.

\section{Results and Discussion}

Diastereomers. The contribution of a change in the distribution of diastereomer resonances upon protein binding was investigated by reducing the number of biosensor diastereomers from four to two by replacing the cysteine maleimide linkage 
between the cage-peptide and the biotinylated linker in 1 with a lysine-amide bond linkage. This new biosensor construct, 2, has only two diastereomers, RL and LL. When titrated with avidin the two diastereomeric peaks from this biosensor shift downfield, from $65.1 \mathrm{ppm}$ and $64.5 \mathrm{ppm}$ with linewidths of $24 \mathrm{~Hz}$ and $25 \mathrm{~Hz}$, respectively, to $67.9 \mathrm{ppm}$ and $66.4 \mathrm{ppm}$ with linewidths of $43 \mathrm{~Hz}$ and $35 \mathrm{~Hz}$, respectively (Figure 1). Avidin binding to 2 shifts the downfield peak by $2.8 \mathrm{ppm}$ and the upfield peak by $1.9 \mathrm{ppm}$. Each diastereomer undergoes a different change in chemical shift, thus separation of the diastereomer peaks increases from $0.6 \mathrm{ppm}$ to $1.5 \mathrm{ppm}$ upon avidin binding. Based on calculations by Harris and coworkers, this increase in diastereomer separation may arise from different increases in the electrostatic potential that protein-bound, encapsulated xenon experiences. ${ }^{[8]}$ The difference in biosensor linewidths likely arises from biosensor diastereomers having different xenon binding properties, which was first observed for functionalized cryptophane-A diastereomers by Huber et al. ${ }^{[9]}$ The xenon spectra for avidin-bound constructs 1 and $\mathbf{2}$ (Figure S1 and Figure 1, respectively) indicate that a significant source of linewidth for construct 1 is an increase in the spread of avidin-bound shifts for diastereomer resonances. These data indicate that the protein-bound form of 
the xenon biosensor can provide signal-to-noise comparable to the protein-free form, and that minimizing the number of biosensor diastereomers is critical for obtaining good signal to noise. For highest sensitivity, the optimal xenon biosensor should consist of a single diastereomer, which can be made by using a pure enantiomer of cryptophane-A. ${ }^{[10]}$

Linker Flexibility. Although the avidin-bound diastereomers of construct $\mathbf{2}$ remain fairly sharp (Figure 1), there is a $14 \mathrm{~Hz}$ increase in the linewidth of each peak upon avidin binding. A change in the xenon exchange rate was ruled out as the source of the increased linewidth for the protein-bound sensor by determining the exchange rates for both protein-free and protein-bound forms. ${ }^{[6]}$ This increase in linewidth likely arises from correlation-time dependent relaxation mechanisms. The molecular nature of the linker can be expected to determine the extent of motional coupling between the cage and protein. If the linker acts as a rigid connection between the cage and avidin then the cage motion will be the same as the protein, a correlation time of $\sim 30$ ns for the avidin tetramer (experimental methods). However, if the linker is flexible then the cage can reorient rapidly, independently of the protein, leading to a decreased correlation time and narrower line. 
The effect of linker rigidity on biosensor linewidth was determined by characterization of biosensor construct $\mathbf{3}$, analogous to $\mathbf{2}$ but with a six-glycine linker between the cagepeptide and biotin. The six planar peptide bonds in the linker of 3 restrict the rotational motion of the biosensor when bound to avidin. Figure 2 shows the spectra of construct 3 in the absence and presence of avidin. In the absence of avidin, there are two narrow peaks, $35 \mathrm{~Hz}$ and $24 \mathrm{~Hz}$, separated by 1 ppm, which correspond to the two biosensor diastereomers, RL and LL. Upon avidin binding four biosensor peaks of larger linewidth $(45 \mathrm{~Hz}$ to $55 \mathrm{~Hz}$ ) and unequal intensity appear. The relative amounts of the diastereomers are equal (Figure 2a), therefore each diastereomer must give rise to one large and one small peak when bound to avidin (Figure 2b). The source of the two smaller peaks was investigated by preparing a sample in which most of the protein-bound construct 3 was bound at a ratio of one molecule per avidin (see experimental methods). The corresponding ${ }^{129} \mathrm{Xe}$ NMR spectrum was similar to that shown in Figure 2b, but the intensities of the two smaller peaks were significantly diminished (data not shown). This observation and the close proximity of two biotin binding sites on avidin (Figure 5a), indicate that the smaller peaks in Figure 2b arise from two biosensor molecules being bound in close proximity. 
More flexible linkers, as in $\mathbf{2}$ and 5, allow more independent motion of the cage, reducing the effects of neighboring ligands on one another. Because this effect may only arise from binding two biosensors in close proximity of each other and can be avoided by using a flexible linker, it was not investigated further.

The increase in linewidth of $\sim 25 \mathrm{~Hz}$ for construct 3 upon avidin binding is larger than that for construct 2 ( 14 $\mathrm{Hz})$. This likely arises from an increased correlation time resulting from the more rigid glycine linker. Because linker flexibility affects protein-bound biosensor linewidth the conformational constraint from the planar succinimide ring in construct 1 probably makes its behavior less than optimal relative to other linkers of similar length.

Linker Length. The correlation time for the avidin-bound biosensor will also be affected by the length of the linker between the cage and the surface of avidin. Even if the linker is flexible a shorter linker will restrict cage motion due to proximity to the protein surface. Simulations by Sears and Jameson indicate that contact between the protein surface and the cage also influences the chemical shift of the encapsulated xenon. ${ }^{[8]}$ Therefore, a decrease in linker length should also 
lead to an increase in chemical shift change upon binding of encapsulated xenon to avidin.

The effect of linker length on biosensor linewidth and chemical shift was explored by comparing the protein-bound properties of biosensors with three different linker lengths. The three constructs, 2, 4, and 5, have two diastereomers and linkers of comparable flexibility. Construct $\mathbf{2}$ has an intermediate linker length, with the cage $\sim 23 \AA$ from the protein surface, and yields two resolved protein-bound resonances that shift over 2 ppm and broaden by $\sim 14 \mathrm{~Hz}$ upon avidin binding (Figure 1). Construct 4 lacks a linker between biotin and the cage-peptide, so that the cage is $\sim 8 \AA$ from the protein. Free sensor and avidin-bound ${ }^{129} \mathrm{Xe}$ spectra from 4 are shown in Figure 3. The protein-free spectrum shows that there is an unequal mixture of the two diastereomers, which most likely is a result of the purification process in which a narrow HPLC fraction was collected, partially separating the diastereomers. Comparison with the protein bound spectrum shows that the upfield and downfield diastereomers retain their relative chemical shifts upon avidin binding. When construct $\mathbf{4}$ binds avidin its resonances broaden from $\sim 15 \mathrm{~Hz}$ to $\sim 125 \mathrm{~Hz}$ and shift from 62.3 ppm and $62.9 \mathrm{ppm}$ to $\sim 65 \mathrm{ppm}$ and $\sim 67 \mathrm{ppm}$, respectively. The increase in linewidth by $110 \mathrm{~Hz}$ limits the accuracy of the 
measurement of the change in chemical shift, but it is apparent that the upfield and downfield diastereomers shift by $\sim 3$ ppm and 〜4 ppm, respectively, which are the largest chemical shift changes observed for a xenon biosensor. The decrease in linker length correlates with an increase in both linewidth and chemical shift sensitivity to avidin binding. Construct $\mathbf{5}$ has a linker composed of twelve ethylene glycol units, putting the cage $\sim 55 \AA$ from the protein surface. When 5 is titrated with avidin there is no change in the shifts of the xenon biosensor resonances (Figure 4) and the linewidth narrows slightly from $\sim 28 \mathrm{~Hz}$ to $\sim 22 \mathrm{~Hz}$. The lack of linewidth and chemical shift sensitivity of construct 5 to avidin binding indicates that there is a maximal linker length for cage-encapsulated xenon's sensitivity to avidin binding .

To better visualize the protein-bound biosensor, constructs 2, 4, and $\mathbf{5}$ were modeled into the biotin-binding site of avidin. [11] The biosensor was modeled with a fully extended linker, so these models show the maximum distance the cage can be from the surface of the protein. Although these models are not energy-minimized structures, they serve as qualitative comparisons for biosensors with different linker lengths. Figure 5a and 5b show a close view of the avidin-bound biosensor model for biosensors 2 and $\mathbf{4}$, respectively. For these the 
maximum distance the cage can be from the protein surface is $\sim 25$ $\AA$ and $\sim 8 \AA$, respectively. Because the four biotin binding sites in avidin are assymetrically distributed, two of the biosensors are in proximity (Figure 5a). This probably contributes to the restriction of rotational motion of the biosensor. Figure 5c shows avidin bound to four biosensor $\mathbf{5}$ molecules, for which the maximum protein-to-cage distance is $\sim 50 \AA$.

Simulations by Sears and Jameson reproduced the magnitude and direction of the chemical shift change of the xenon biosensor upon avidin binding by decreasing the internal volume of the cage. ${ }^{[8]}$ Their results indicate that contact of the cage with the protein surface may be the primary mechanism of xenon biosensor chemical shift sensitivity to avidin binding. Although none of the biosensors studied has a short enough linker to cause the cage to be in direct contact with the surface of the protein all of the time, the inverse proportionality between the linker length and chemical shift sensitivity is in agreement with a contact-mediated binding induced shift.

Partial Cage Deuteration. The increase in the linewidth for biosensor resonances when bound to protein indicates that there is an increase in $\mathrm{T}_{2}$ relaxation rate upon protein binding. An 
increase in the rate of xenon exchange into the cage has been previously ruled out as a source of relaxation. ${ }^{[6]}$ The likely relaxation mechanisms are dipole-dipole coupling and chemical shift anisotropy (CSA) .

The contribution of dipole-dipole coupling between encapsulated xenon and cage protons can be calculated using the estimated correlation time of the xenon biosensor (see experimental methods) and the xenon-proton internuclear distances that have been previously reported for cryptophane-A dissolved in $\left(\mathrm{CDCl}_{2}\right)_{2}$ based on SPINOE measurement.s. ${ }^{[12]}$ The validity of the assumption that the internuclear distances do not significantly change when the cage is functionalized, dissolved in water, and bound to avidin will be discussed below. The rate of proton-xenon cross relaxation for the biosensor can be calculated using the following relationships,

$$
\begin{aligned}
& \sigma_{H X e}=\sum_{i} \sigma_{H X e}(i) \\
& \sigma_{H X e}(i)=\frac{d_{00}}{8}\left\{4 J(0)+J\left(\omega_{H}-\omega_{X e}\right)+3 J\left(\omega_{X e}\right)+6 J\left(\omega_{H}\right)+6 J\left(\omega_{H}+\omega_{X e}\right)\right\} \\
& \text { with } d_{00}=\left(\frac{\mu_{0} \hbar \gamma_{H} \gamma_{X e}}{4 \pi}\right)^{2}\left\langle\frac{1}{r(i)^{6}}\right\rangle \\
& \text { and } \quad J(\omega)=\frac{2 \tau_{C}}{5\left(1+\omega^{2} \tau_{C}^{2}\right)}
\end{aligned}
$$

where $\sigma_{H x e}$ is the total proton-xenon cross relaxation rate, 
$\sigma_{H X e}(i)$ is the proton-xenon cross relaxation rate for the ith proton, $\left\langle r(i)^{-6}>\right.$ is the average internuclear distance for the $i$ th proton, and $\tau_{c}$ is the correlation time for rotation of the biosensor. ${ }^{[13]}$ The $\left\langle r(i)^{-6}\right\rangle$ values that have been previously determined $^{[12]}$ were used to calculate estimates of $\sigma_{H X e}$ for the protein-free biosensor, with $\tau_{c} \sim 1.6 \mathrm{~ns}$, and the protein-bound biosensor, with $\tau_{c} \sim 30$ ns (experimental methods). $\sigma_{H X e}$ is 0.07 $\mathrm{Hz}$ and $0.8 \mathrm{~Hz}$ for the protein-free and protein-bound biosensors, respectively. These predicted values for dipolar broadening are well below the experimental values indicating that $\mathrm{H}-\mathrm{Xe}$ dipoledipole coupling does not contribute significantly to biosensor relaxation.

The contribution of dipole-dipole coupling to biosensor linewidth was also tested experimentally using a partially deuterated version of construct 2, designated $\mathbf{2}$, in which the methoxy and linker protons were deuterated (Scheme 1). The calculated differences in $\sigma_{H x e}$ values predicted for partially deuterated free and avidin-bound 2* $(0.03 \mathrm{~Hz}$ and $0.4 \mathrm{~Hz})$ are within the error of linewidth measurement (4 Hz), indicating that the linewidths of $\mathbf{2}^{*}$ and $\mathbf{2}$ should be the same. Comparison of the linewidths of free and avidin-bound $2 *(\sim 19 \mathrm{~Hz}$ and $\sim 37$ $\mathrm{Hz}$, respectively, Figure S2) with those for construct 2 ( 24 Hz 
and $\sim 39 \mathrm{~Hz}$ ) indicates that dipole-dipole coupling does not contribute significantly to protein-bound linewidth. This is a result of the relatively large average proton-xenon internuclear distance for encapsulated xenon ( $5 \pm 0.7 \AA)$ leading to weak dipolar coupling because of the $\left\langle r(i)^{-6}\right\rangle$ dependence.

Temperature Dependence. The contribution of xenon exchange to biosensor linewidth was probed by measuring the temperature dependence of free and avidin-bound biosensor resonances for construct 2*. As shown in Figure 6, both the linewidth and chemical shift of the xenon biosensor depend on temperature. The chemical shift of construct 2 * for both free and avidinbound forms depends linearly on temperature between $10^{\circ} \mathrm{C}$ and $40^{\circ} \mathrm{C}$ with a slope of $0.27 \mathrm{ppm} /{ }^{\circ} \mathrm{C}$ (Figure $\mathrm{S3}$ ), which is the same as that for cryptophane-A-encapsulated xenon in deuterated tetrachloroethane $\left(\sim 0.28 \mathrm{ppm} /{ }^{\circ} \mathrm{C}\right) .{ }^{[14]}$ Temperature dependence of encapsulated xenon is thought to arise from increased xenon sampling of the repulsive regions of the xenon-cryptophane potential and an increase in cryptophane-A molecules in higher energy conformations. ${ }^{[14,15]}$ The similarity of temperaturedependent chemical shift for cryptophane-A dissolved in $\left(\mathrm{CDCl}_{2}\right)_{2}$ and cryptophane-A that has been functionalized, dissolved in water, and protein-bound suggests that the structure and 
interactions of the cage and encapsulated xenon are similar in these different environments. This supports the previous assumption that the internuclear distances between encapsulated xenon and cage protons are similar in different constructs and solvents.

As shown in Figure 6, the linewidth for avidin-free construct 2* increases significantly with temperature above $25^{\circ} \mathrm{C}$, indicating that the exchange rate reaches a rate of $\geq 30 \mathrm{sec}^{-1}$ so that exchange broadening significantly contributes to proteinfree biosensor linewidth (see also Figure S4a). From $10^{\circ} \mathrm{C}$ to $25^{\circ} \mathrm{C}$ the biosensor linewidth decreases slightly with temperature, indicating correlation time dependent mechanisms dominate at these temperatures. Figure 6 also shows that the linewidth of the protein-bound biosensor 2* is not significantly temperature dependent from $10^{\circ} \mathrm{C}$ to $35^{\circ} \mathrm{C}$, indicating that a relaxation mechanism other than exchange must dominate at low temperatures (see also Figure S4b).

Similar measurements were made for the avidin-free and avidin-bound forms of constructs 3 and $\mathbf{5}$. The linewidth and chemical shift for the avidin-free form of construct $\mathbf{3}$ and both the avidin-free and avidin-bound forms of construct $\mathbf{5}$ exhibited similar behavior to that observed for the avidin-free form of construct 2*. However, the resonances for the avidin-bound form 
of construct 3 were the narrowest at $23^{\circ} \mathrm{C}$ and broadened when the temperature was increased and decreased by $10^{\circ} \mathrm{C}$ (Figure S5), again indicating a combination of mechanisms as for $2 *$.

The temperature dependence of the linewidth for construct 2* was used to determine the xenon exchange rates above $25^{\circ} \mathrm{C}$ for protein-free biosensor. Exchange affects linewidth according to the relationship

$$
\Delta v_{1 / 2}=\left(\pi \tau_{e x}\right)^{-1}
$$

where $\Delta v_{1 / 2}$ is the contribution to the linewidth at half height and $\tau_{\text {ex }}$ is the exchange rate. To calculate $\tau_{\text {ex }}$, the linewidths at high temperature were corrected for linewidth contribution from the low temperature relaxation mechanisms by extrapolating the temperature dependence behavior between $10^{\circ} \mathrm{C}$ and $25^{\circ} \mathrm{C}$ up to $35^{\circ} \mathrm{C}$. The exchange contributions to linewidths were used to calculate $\tau_{\text {ex }}$ at $28^{\circ} \mathrm{C}, 30^{\circ} \mathrm{C}$, and $35^{\circ} \mathrm{C}$. For temperatures below $25^{\circ} \mathrm{C} \tau_{e x}$ was determined by measuring the recovery of selectively saturated xenon signals, as described previously. ${ }^{[6]}$ The temperature dependent exchange rates were used to obtain an activation energy for xenon dissociation from the cryptophane complex in water of $121 \pm 7 \mathrm{~kJ} / \mathrm{mol}$. This is approximately three times higher than that determined for xenon-cryptophane-A decomplexation in $\left(\mathrm{CDCl}_{2}\right)_{2}, 37 \mathrm{~kJ} / \mathrm{mol}$, ${ }^{[16]}$ one cause of which may 
be a higher enthalpic cost for dissolution of xenon in water.

Other Relaxation Contributions for the Protein-Bound

Biosensor. The dipolar $(\sim 1 \mathrm{~Hz})$ and exchange $(\sim 7 \mathrm{~Hz})$

contributions to the linewidths for xenon in the protein-bound biosensor $\mathbf{2}$ are not sufficient to explain the observed value of $\sim 32 \mathrm{~Hz}$ (corrected for inhomogeneous broadening from field inhomogeneity estimated from the ${ }^{1} \mathrm{H}$ linewidth in $\mathrm{D}_{2} \mathrm{O}$ in the sample). Chemical shift anisotropy (CSA) was also considered as a possible contributing mechanism. The contribution of CSA to xenon linewidth can be significant due to the extraordinary chemical shift sensitivity of xenon to its local environment. The CSA value required for a given linewidth can be calculated from the following relationship:

$$
R_{2}=\frac{1}{18}\left\{\Delta \sigma_{C S A}^{2} \omega_{X e}^{2}\left(4 J(0)+3 J\left(\omega_{X e}\right)\right)\right\}
$$

where $\left(R_{2}\right)$ is the linewidth in $\mathrm{Hz}, \Delta \sigma_{C S A}$ is the chemical shift anisotropy in ppm, $\omega_{\mathrm{Xe}}$ is the resonant frequency of ${ }^{129} \mathrm{Xe}$ at $7 \mathrm{~T}$ $(2 \pi * 82.9 \mathrm{MHz})$, and $J(\omega)$ is estimated from the correlation time, Equation (1d). ${ }^{[13]}$ Using the $\sim 30$ ns estimated $\tau_{\mathrm{c}}$ for the avidinbound biosensor $\mathbf{2}^{*}$ and the $24 \mathrm{~Hz}$ observed excess linewidth, a $\Delta \sigma_{\mathrm{CSA}}$ value of $\sim 180 \mathrm{ppm}$ was calculated. This value seems unrealistically large for xenon inside a deformed cryptophane-A 
cage. Reported ${ }^{129} \mathrm{Xe}$ CSA values range from 10 ppm to over 150 ppm, but those larger than tens of ppm are for xenon inside fully occupied nanochannels where xenon-xenon interactions dominate the CSA term. ${ }^{[17]}$ Further experiments are needed to directly establish the protein-bound cryptophane-encapsulated ${ }^{129} \mathrm{Xe}$ CSA.

Another possible contribution to bound biosensor linewidth is conformational exchange. The fact that multiple peaks are seen for bound biosensor $\mathbf{3}$ emphasizes the sensitivity of encapsulated

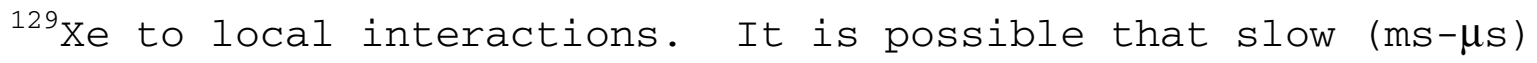
fluctuations among multiple bound conformations also contributes to the linewidth for other biosensors. Studies of other linkers, and proteins with single binding sites, are probably needed to resolve this issue.

\section{Conclusions}

Optimizing the design of the xenon biosensor construct has allowed signals from avidin-bound biosensor diastereomers to be resolved, demonstrating the feasibility of obtaining narrow lines from protein-bound xenon biosensors. The structural details of the biosensor linker significantly influence the linewidth and chemical shift sensitivity of the protein-bound xenon biosensor. The characteristics of the constructs surveyed 
here indicate that a flexible linker of moderate length, such as that used in constructs $\mathbf{2}$ or $\mathbf{5}$, can lead to reasonably narrow lines for protein-bound xenon biosensor. Depending on the desired application, the chemical shift sensitivity of the xenon biosensor can be tuned by using a shorter or longer linker. The relaxation mechanisms contributing to the linewidth for the avidin-bound biosensor include bulk-to-cage xenon exchange, biosensor conformational exchange, and possibly CSA. The exchange contribution is inherent since xenon must be able to enter the cage for the biosensor to function; however, it may be possible to modify the cage to decrease the rate of exchange without significantly altering the xenon binding affinity. Conformational exchange contributions seem to be eliminated in biosensor molecules with longer, flexible linkers. They may also disappear for targets with single biosensor binding sites. Understanding the parameters for obtaining good signal-to-noise for protein-bound cryptophane-encapsulated xenon is critical for applications that require protein-functionalization, such as affinity-targeting with antibodies ${ }^{[7,18]}$ or metabolite sensing with engineered periplasmic binding proteins, ${ }^{[19]}$ at in vivo concentrations.

\section{Experimental Methods}


Cryptophane-A carboxylic acid ${ }^{[6]}$ and partially deuterated cryptophane-A carboxylic acid ${ }^{[20]}$ were synthesized as previously described. The complete synthesis of construct $1^{[6]}$ and construct $3^{[21]}$ have been previously described. For constructs 2 and 4, the cryptophane-A carboxylic acid was attached to the deprotected N-terminus of a hydrophilic peptide $\left.\left[\mathrm{NH}_{2} \mathrm{~K}(\mathrm{Cbz}) \mathrm{R}(\mathrm{Pbf}) \mathrm{K}(\mathrm{BOC}) \mathrm{R}(\mathrm{Pbf}) \mathrm{CO}_{2} \mathrm{Me}\right)\right]$ using PyBOP and $\mathrm{N}-$ methylmorpholine in DMF. The peptide was synthesized by conventional solid-phase peptide chemistry using trityl resin (Fmoc chemistry; PyBOP/DIEA acylation; deprotection with $20 \%$ piperidine in DMF; resin cleavage with AcOH/trifluoroethanol/DCM (1:1:8); esterification of C-terminus using diazomethane; deprotection of $\mathrm{N}$-terminus with piperidine in DMF; purification by reversed-phase HPLC). The Cbz protecting group was then cleaved under hydrogenation conditions $\left(\mathrm{H}_{2}, \mathrm{Pd} / \mathrm{C}\right)$. The cryptophane-A-peptide construct was biotinylated by reacting the unprotected lysine side chain with NHS-LC-LC-Biotin (Pierce Chemical) in DMF in presence of DIEA, for construct 2, or with biotin, for construct 4, deprotected with TFA/Me $\mathrm{M}_{2} \mathrm{~S}$ thioanisole (18:1:1), and purified by reversed-phase HPLC. For construct 5, the cryptophane-A carboxylic acid was attached to the deprotected terminus of a small hydrophilic peptide [ $\left.\mathrm{KR}_{3} \mathrm{COOH}\right]$ that was synthetized by conventional solid-phase methods (Fmoc 
chemistry; DCC/HOBT/NMP acylation; deprotection in TFA with water/thioanisole; purity of crude product was >95\% by FTICRMS). The cage-peptide construct was biotinylated by reaction with HBTU/HOBT/DIEA/N-Fmoc-amino-dPEG 12 -acid (Quanta Biodesign), deprotected with piperidine/NMP, and reacted with HBTU/HOBT/DIEA/biotin .

Hyperpolarized ${ }^{129} \mathrm{Xe}$ NMR spectroscopy was conducted using the stopped-flow bubble mode apparatus and a $300 \mathrm{MHz}$ (proton frequency) Varian Inova spectrometer and a Amersham Health ${ }^{129} \mathrm{Xe}$ polarizer, which produced $\sim 3 \%$ polarized ${ }^{129} \mathrm{Xe}$, as previously described. [21] All spectra were referenced to xenon gas at 0 ppm, fitted using matNMR, and processed with a $10 \mathrm{~Hz}$ exponential filter, unless otherwise noted. The solution peak for all spectra was at 191 ppm for solutions in $50 \% \mathrm{D}_{2} \mathrm{O}, 50 \% \mathrm{H}_{2} \mathrm{O}$, and at 189 ppm for solutions in 99\% $\mathrm{D}_{2} \mathrm{O}$, and typically had a linewidth of $\sim 10 \mathrm{~Hz}$. Unless otherwise noted, errors for chemical shifts were $\pm 0.1 \mathrm{ppm}$ and linewidths $\pm 4 \mathrm{~Hz}$. The chemical shift of the solution-dissolved xenon peak changed with temperature by less than $0.04 \mathrm{ppm} /{ }^{\circ} \mathrm{C}$ between $10^{\circ} \mathrm{C}$ and $40^{\circ} \mathrm{C} . \sim 10 \% 1$-Propanol was added to biosensor solutions for constructs $\mathbf{3}$ and $\mathbf{5}$ to suppress sample foaming during xenon bubbling. Sample concentrations were determined with UV-vis spectrophotometry using molar absorptivity coefficients of $8,000 \mathrm{M}^{-1}$ for pure biosensor ${ }^{[6]}$ and 
$96,000 \mathrm{M}^{-1}$ for pure avidin (Sigma). ${ }^{[22]}$ The sample in which one molecule of construct 3 was bound per avidin was prepared by adding one equivalent of construct 3 to a dilute solution of two equivalents of avidin tetramer, or eight equivalents of biotin binding sites, during mixing. Because the biotin-binding sites were in excess and avidin binds biotin in a non-cooperative manner, ${ }^{[23]}$ most biosensor was assumed to be bound at a ratio of one molecule per avidin.

Molecular models of the biosensor constructs were built with PyMOL $^{[24]}$ and docked into the crystal structure of biotin-bound avidin ${ }^{[1]}$ by overlaying the biosensor-tethered biotin with avidin-bound biotin and positioning the biosensor linker in the biotin binding channel. No energy minimization on the biosensor or biosensor-avidin construct was done.

The correlation time of the protein-free and protein-bound biosensor can be estimated according to the following relationships:

$$
\begin{aligned}
\tau_{C} & =\frac{4 \pi \eta_{W} r_{H}^{3}}{3 k_{B} T} \\
r_{H} & =\left(\frac{3 \bar{V} M_{r}}{4 \pi N_{A}}\right)^{1 / 3}+r_{W}
\end{aligned}
$$

where $\tau_{C}$ is the correlation time, $\eta_{w}$ the viscosity of water, $r_{H}$ the effective radius, $\bar{V}$ the specific volume, $M_{r}$ the molecular 
weight, and $r_{w}$ the thickeness of a single hydration sphere for water. [13] Accordingly, the correlation times for the avidin-free $\left(M_{Y}=\sim 2 \mathrm{kDa}\right)$ and avidin-bound $\left(M_{r}=\sim 74 \mathrm{kDa}\right)$ xenon biosensor was calculated to be $\sim 1.6$ ns and $\sim 30$ ns, respectively.

\section{Acknowledgements}

The authors thank Cynthia Jameson and Devin Sears for their helpful discussions regarding chemical shift anisotropy of xenon. E.R. acknowledges Lucent Technologies for a pre-doctoral fellowship, and T.L. acknowledges University of California Biotechnology Research and Education Program for a training grant. This work was supported by the Director, Office of Science, Office of Basic Energy Sciences, Materials Sciences Division and Physical Biosciences Division of the U.S. Department of Energy under Contract No. DE-AC03-76SF00098.

\section{References}

[1] J. M. Perez, L. Josephson, T. O'Loughlin, D. Hogemann, R. Weissleder, Nat. Biotechnol. 2002, 20, 816-820.

[2] A. Y. Louie, M. M. Huber, E. T. Ahrens, U. Rothbacher, R. Moats, R. E. Jacobs, S. E. Fraser, T. J. Meade, Nat. Biotechol. $2000,18,321-325$

[3] K. Golman, J. H. Ardenaer-Larsen, J. S. Petersson, S. 
Mansson, I. Leunbach, Proc. Nat1. Acad. Sci. USA 2003, 100, $10435-10439$.

[4] a) M. S. Albert, G. D. Cates, B. Dreihuys, W. Happer, B. Saam, C. S. Springer, A. Wishnia, Nature 1994, 370, 199-201; b) M. S. Chawla, X. J. Chen, H. E. Moller, G. P. Cofer, C. T. Wheeler, L. W. Hedlund, G. A. Johnson, Proc. Natl. Acad. Sci. USA 1998, 95, 10832-10835.

[5] M. M. Spence, S. M. Rubin, I. E. Dimitrov, E. J. Ruiz, D. E. Wemmer, A. Pines, S. Q. Yao, F. Tian, P. G. Schultz, Proc. Natl. Acad. SCi. USA 2001, 98, 10654-10657.

[6] M. M. Spence, E. J. Ruiz, S. M. Rubin, T. J. Lowery, N. Winssinger, P. G. Schultz, D. E. Wemmer, A. Pines, J. Am. Chem. SoC. 2004, 126, 15287-15294.

[7] T. J. Lowery, S. M. Rubin, E. J. Ruiz, M. M. Spence, N. Winssinger, P. G. Schultz, A. Pines, D. E. Wemmer, Magn. Reson. Imaging 2003, 21, 1235-1239.

[8] D. N. Sears, C. J. Jameson, R. A. Harris, J. Chem. Phys. $2004,120,3277-3283$

[9] J. G. Huber, L. Dubois, H. Desvaux, J. P. Dutasta, T. Brotin, P. Berthault, J. Phys. Chem. A 2004, 108, 9608-9615. [10] T. Brotin, R. Barbe, M. Darzac, J. P. Dutasta, Chem. Eur. J. 2003，9，5784-5792.

[11] L. Pugliese, A. Coda, M. Malcovati, M. Bolognesi, J. Mol 
Biol. 1993, 231, 698-710.

[12] M. Luhmer, B. M. Goodson, Y. Q. Song, D. D. Laws, L.

Kaiser, M. C. Cyrier, A. Pines, J. Am. Chem. Soc. 1999, 121, $3502-3512$.

[13] J. Cavanagh, W. J. Fairbrother, A. G. Palmer III, N. J. Skelton, Protein NMR Spectroscopy, Academic Press, San Diego, 1996, pp 17-18, 267-279.

[14] K. Bartik, M. Luhmer, J. P. Dutasta, A. Collet, J. Reisse, J. Amer. Chem. Soc. 1998, 120, 784-791.

[15] D. N. Sears, C. J. Jameson, J. Chem. Phys. 2003, 119, $12231-12244$

[16] T. Brotin, J.P. Dutasta, Eur. J. Org. Chem. 2003, 973-984.

[17] C. J. Jameson, J. Chem. Phys. 2002, 116, 8912-8929, and references therein.

[18] D. A. Sipkins, D. A. Cheresh, M. R. Kazemi, L. M. Nevin, M. D. Bednarski, KCP Li, Nat. Med. 1998, 4, 623-626.

[19] L. L. Looger, M. A. Dwyer, J. J. Smith, H. W. Hellinga, Nature 2003, 423, 185-190.

[20] T. Brotin, A. Lesage, L. Emsley, A. Collet, J. Amer. Chem. SoC. 2000, 122, 1171-1174.

[21] S.-I. Han, S. Garcia, T. J. Lowery, E. J. Ruiz, J. A. Seeley, L. Chavez, D. S. King, D. E. Wemmer, A. Pines, Anal. Chem. 2005, 77, 4008-4012. 
[22] N. M. Green, Method. Enzymol. 1990, 184, 51-57.

[23] C. Rosano, P. Arosio, M. Bolognesi, Biomol. Eng. 1999, 16, $5-12$.

[24] D. L. DeLano, The PyMol Molecular Graphics System, DeLano Scientific, San Carlos, CA, 2002. 


\section{Figure and Scheme Legends}

Scheme 1. The five different biotinylated xenon biosensor constructs that were synthesized and characterized.

Figure 1. Titration of biosensor 2 with avidin. (a) $140 \mu \mathrm{M} 2$ with peaks at $65.1 \mathrm{ppm}$ and $64.5 \mathrm{ppm}$ and linewidths of $24 \mathrm{~Hz}$ and $25 \mathrm{~Hz}$, respectively; (b) $126 \mu \mathrm{M}$ 2, $16 \mu \mathrm{M}$ avidin tetramer; (c) 109 $\mu \mathrm{M} 2,29 \mu \mathrm{M}$ avidin tetramer, corresponding to fully titrated biosensor, with peaks at 67.9 ppm and $66.4 \mathrm{ppm}$ and linewidths of $43 \mathrm{~Hz}$ and $35 \mathrm{~Hz}$, respectively. All spectra were collected at $23^{\circ} \mathrm{C}, 16$ scans. The two biosensor diastereomers shift downfield and only slightly broaden upon avidin binding of construct 2 . Figure 2. Titration of biosensor 3 with avidin. (a) $82 \mu \mathrm{M} 3$ with peaks at $65.9 \mathrm{ppm}$ and $65.0 \mathrm{ppm}$ and linewidths of 35 and 24 $\mathrm{Hz}$, respectively. (b) $77 \mu \mathrm{M}$ 3, $20 \mu \mathrm{M}$ avidin tetramer, corresponding to fully titrated biosensor, with peaks at 67.4 ppm, $66.5 \mathrm{ppm}, 65.6 \mathrm{ppm}$, and $64.5 \mathrm{ppm}$ and approximate linewidths of $55 \mathrm{~Hz}, 49 \mathrm{~Hz}, 46 \mathrm{~Hz}$, and $57 \mathrm{~Hz}$, respectively. All spectra were collected at $23^{\circ} \mathrm{C}, 16$ scans. Four biosensor resonances appear upon avidin binding of construct 3 from interactions between protein-bound biosensors that are in close proximity. Figure 3. Titration of biosensor 4 with avidin. (a) $72 \mu \mathrm{M}$ of 
construct 4 with peaks at 62.9 ppm and $62.3 \mathrm{ppm}$ and linewidths of $17 \mathrm{~Hz}$ and $12 \mathrm{~Hz}$, respectively. (b) $72 \mu \mathrm{M} \mathbf{4}, 18 \mu \mathrm{M}$ avidin tetramer, corresponding to fully titrated biosensor, with peaks at $67 \mathrm{ppm}$ and $65 \mathrm{ppm}$ and linewidths of $125 \mathrm{~Hz}$. Both spectra were acquired at $20^{\circ} \mathrm{C}$. The protein-free spectrum was acquired with 16 scans and the protein-bound spectrum with 64 scans. The unequal intensities of both diastereomers indicate that their relative positions remain the same after protein binding. The broad protein-bound resonances arise from a short linker that restricts the range of motion of the biosensor.

Figure 4. Titration of biosensor $\mathbf{5}$ with avidin. (a) $50 \mu \mathrm{M} \mathbf{5}$ with two peaks at 66.9 and $66.1 \mathrm{ppm}$ and linewidths of $27 \mathrm{~Hz}$ and 31 $\mathrm{Hz;}$ (b) $50 \mu \mathrm{M}$ 5, $13 \mu \mathrm{M}$ avidin tetramer, corresponding to fully titrated biosensor, with two peaks at $66.9 \mathrm{ppm}$ and $66.0 \mathrm{ppm}$ and linewidths of $24 \mathrm{~Hz}$ and $20 \mathrm{~Hz}$. There is no change in chemical shift and a slight decrease in linewidth for construct 5 upon avidin binding due to a long, flexible linker.

Figure 5. Molecular models of the xenon biosensor bound to avidin. (a) Two biosensor 2 molecules (green) bound to avidin (gray, space-filling). The proximity of two biotin binding sites allows for interaction of two biosensor molecules when bound to avidin. The linker of construct $\mathbf{2}$ keeps the cage within $\sim 23 \AA$ of 
the protein surface. (b) One biosensor 4 molecule (yellow) bound to avidin (gray, space-filling). The second biosensor molecule is not shown for clarity. The linker of construct 4 keeps the cage within $\sim 8 \AA$ of the protein surface and in proximity of the second cage and protein surface. (c) Four biosensor 5 molecules (green) bound to avidin (gray, space-filling, blue cartoon backbone). The linker of construct 5 extends the cage $\sim 50 \AA$ from the protein surface.

Figure 6. Temperature dependence for ${ }^{129} \mathrm{Xe}$ NMR spectra of (a) 105 $\mu \mathrm{M}$ avidin-free and (b) $87 \mu \mathrm{M}$ avidin-bound construct 2*. Spectra for three different temperatures are shown, $35^{\circ} \mathrm{C}$ (solid gray line), $20^{\circ} \mathrm{C}$ (dashed line), and $10^{\circ} \mathrm{C}$ (solid black line). Linewidths of free ${ }^{129} \mathrm{Xe}$ in solution were between 10 and $20 \mathrm{~Hz}$ for all temperatures. Spectra were collected with 4 scans for (a) and 8 scans for (b). At temperatures above $25^{\circ} \mathrm{C}$ the proteinfree biosensor resonance broadens due to xenon exchange. Protein-bound biosensor linewidth is essentially temperature independent over the $10^{\circ} \mathrm{C}$ to $35^{\circ} \mathrm{C}$ range. 


\section{Figure and Text for the Table of Contents}

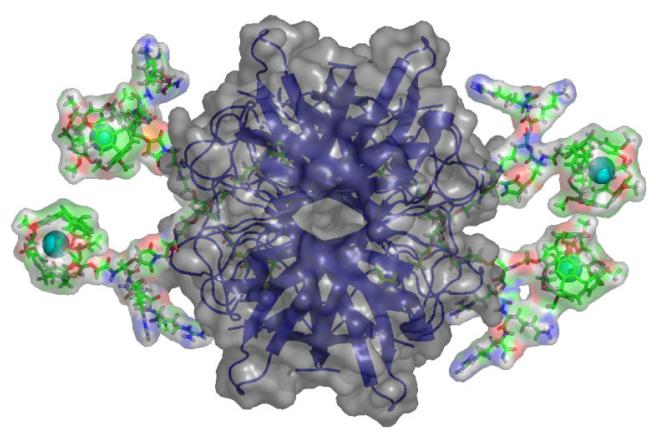

The xenon biosensor can be used as a sensitive, low-background, magnetic resonance detector for biomolecular events. Here we describe the necessary molecular parameters for obtaining optimal signal-to-noise and chemical shift sensitivity from the protein-bound xenon biosensor. 


\section{Figures}
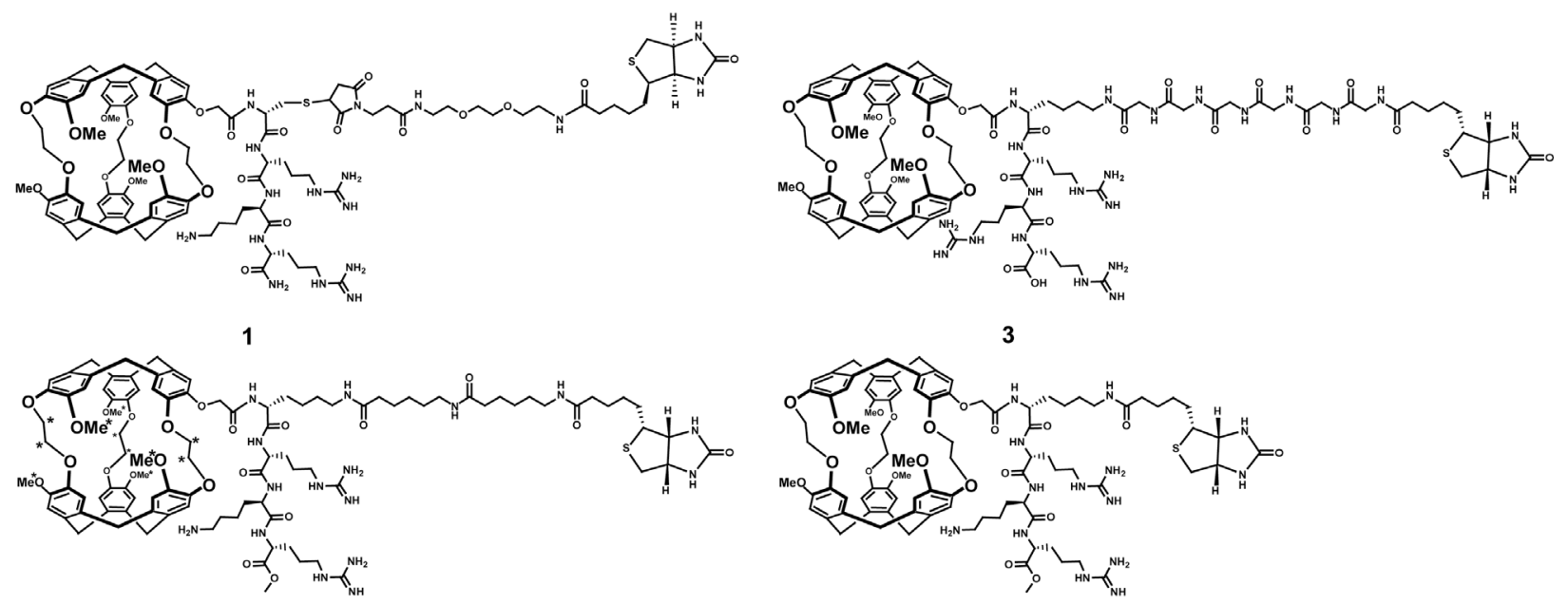

2

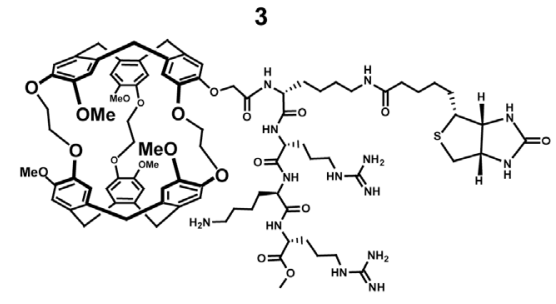

4

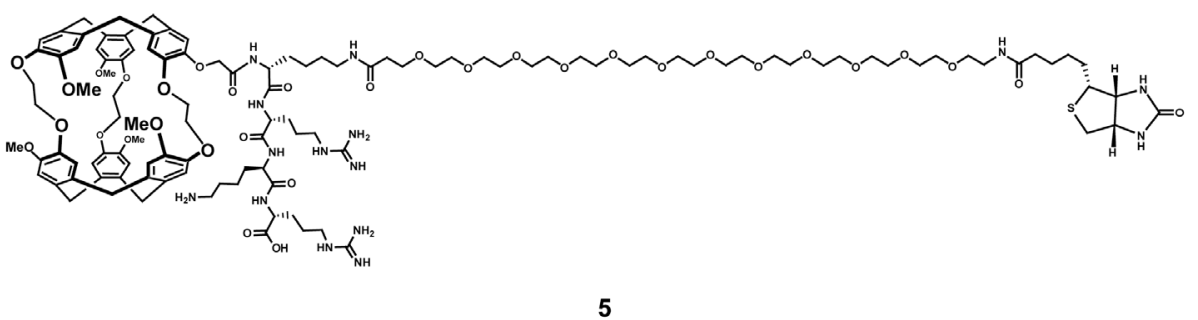

Scheme 1. 

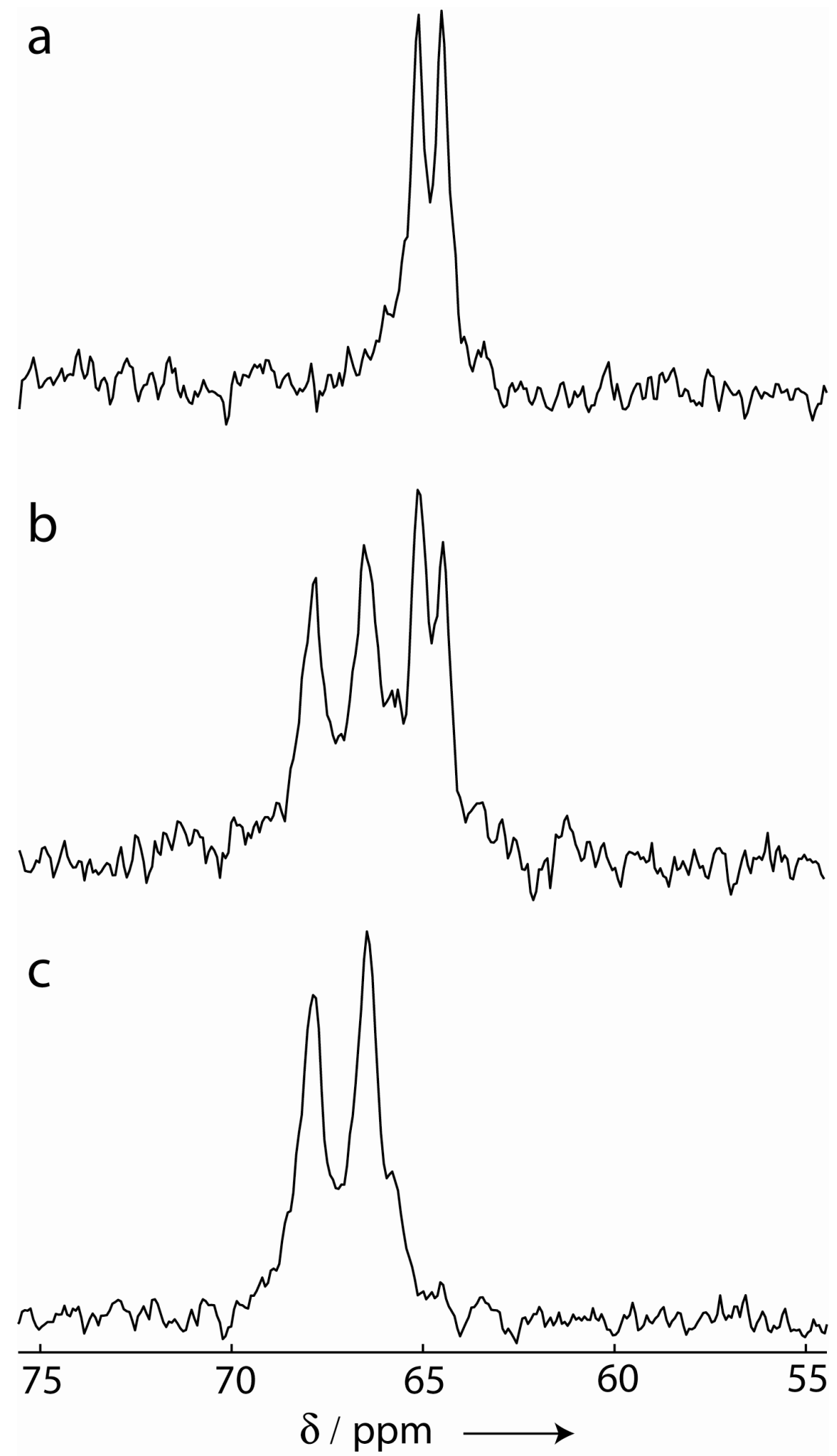

Figure 1.

33 

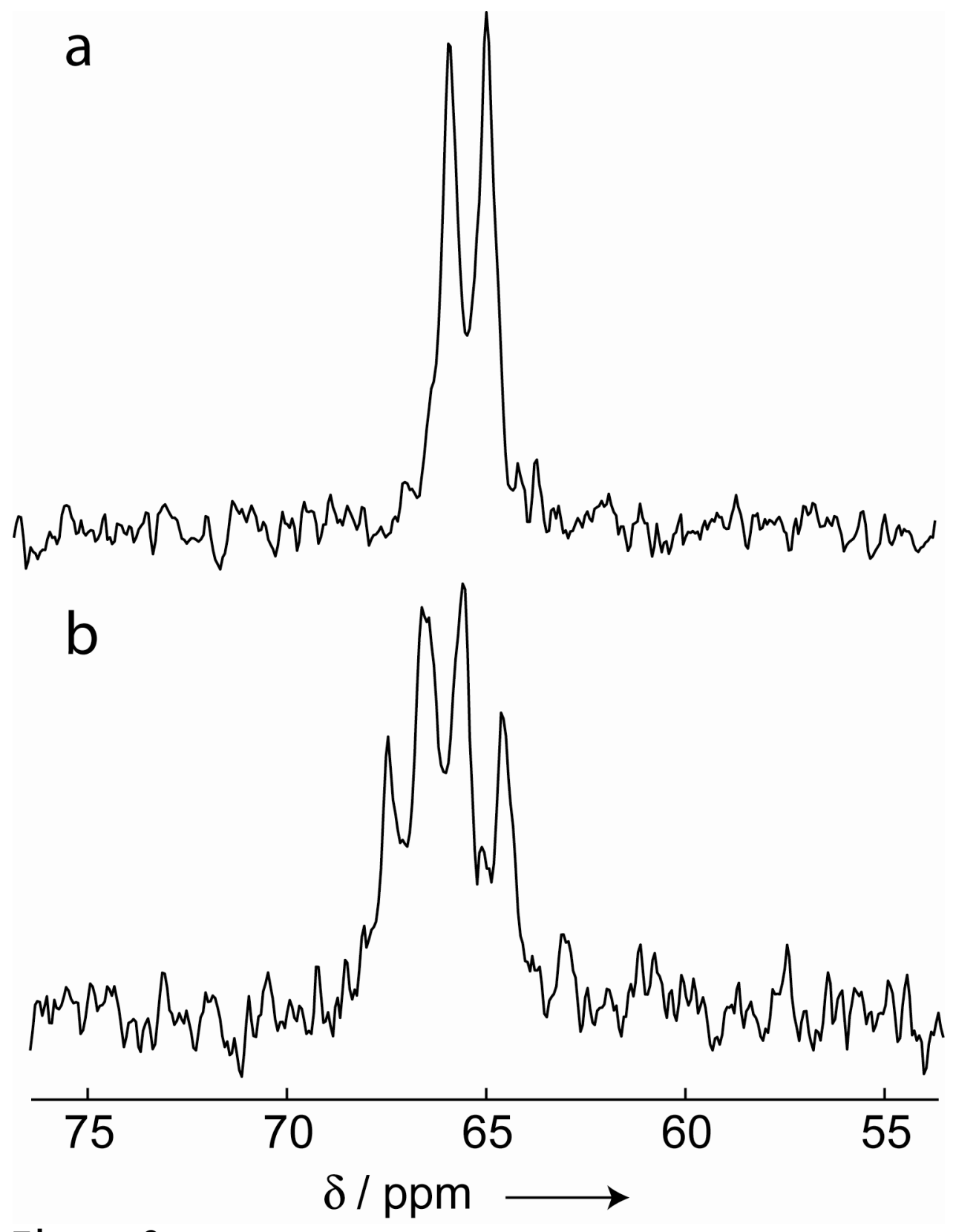

Figure 2 . 

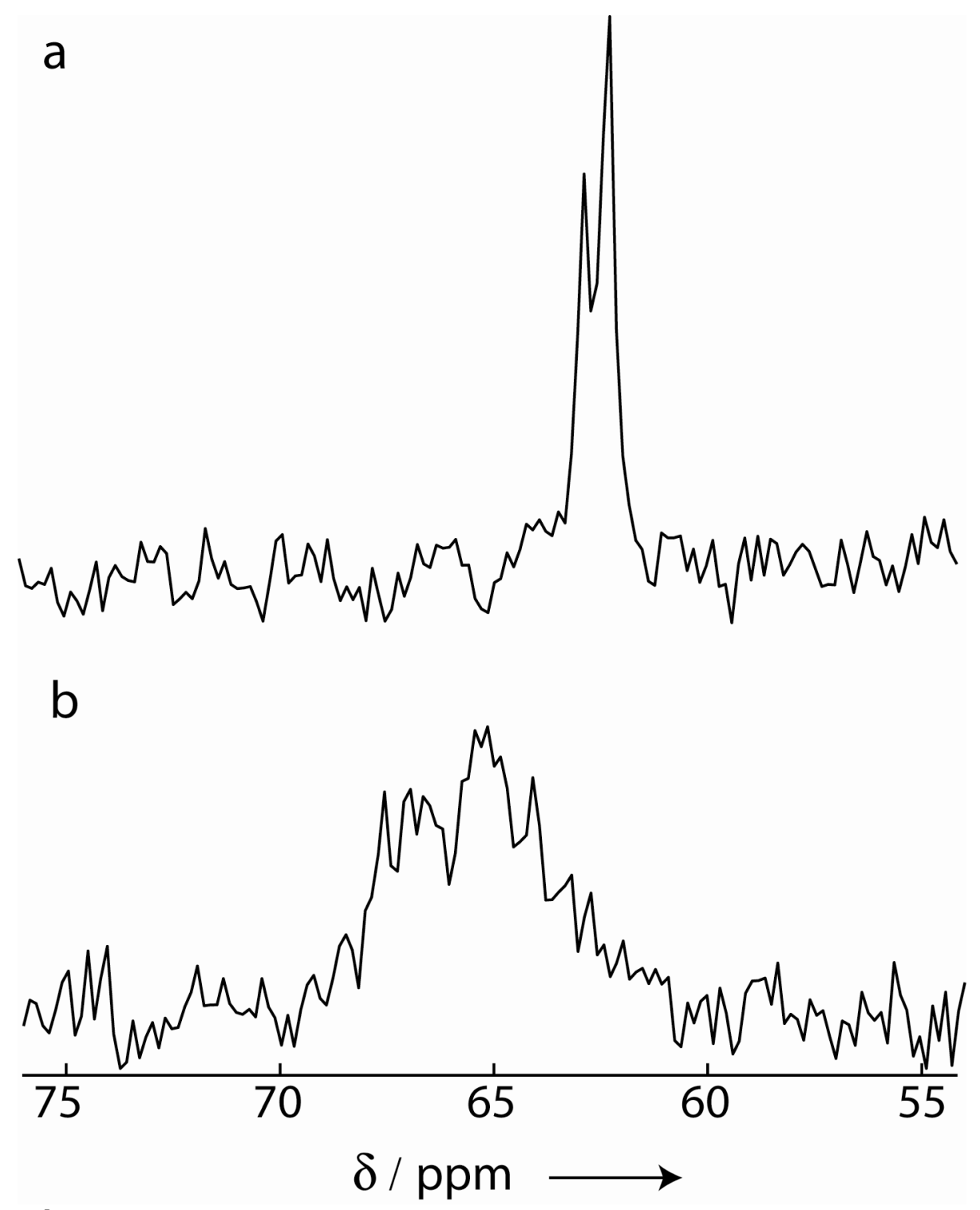

Figure 3 . 

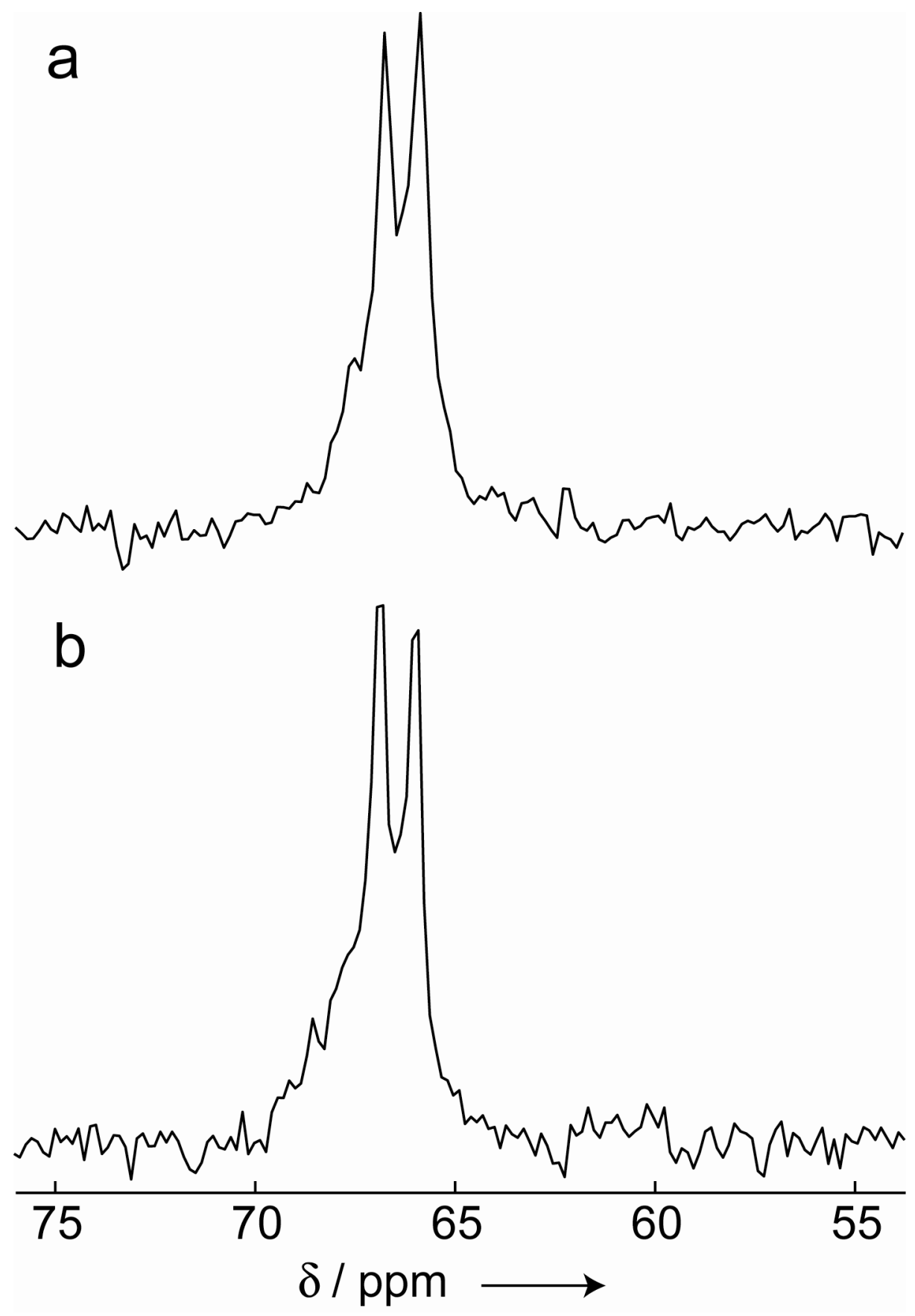

Figure 4 . 

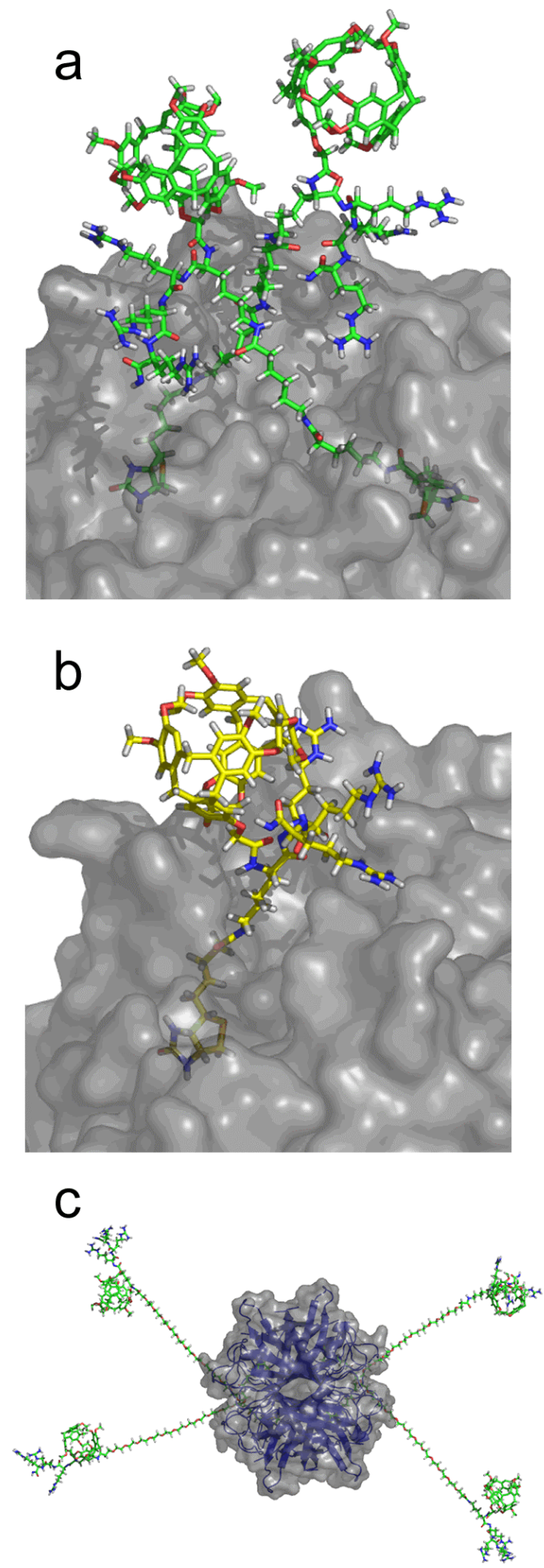

Figure 5. 

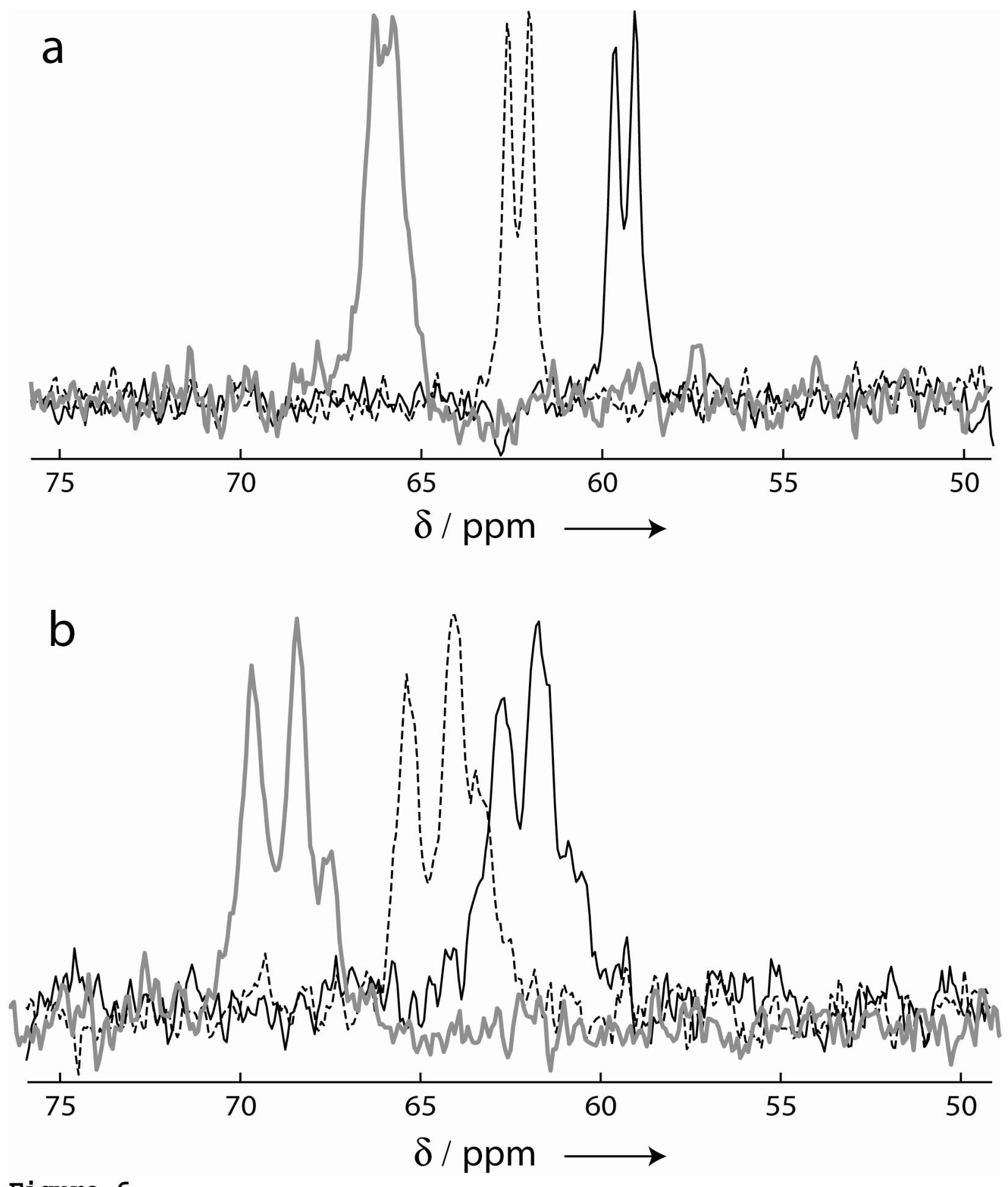

Figure 6 . 


\section{Cover Figure:}

The cover picture shows four xenon biosensor molecules (yellow) bound to the avidin tetramer (gray/blue). Each biosensor binds one hyperpolarized xenon atom (green). The magnetic resonance signal from cage-encapsulated xenon can be used to detect avidin binding with high sensitivity, no background signals, and no interference from other materials in the sample. Optimizing the molecular parameters of the tether between the cage and avidin allows for high sensitivity signal acquisition from proteinfunctionalized xenon, enabling more sophisticated applications of the xenon biosensor.

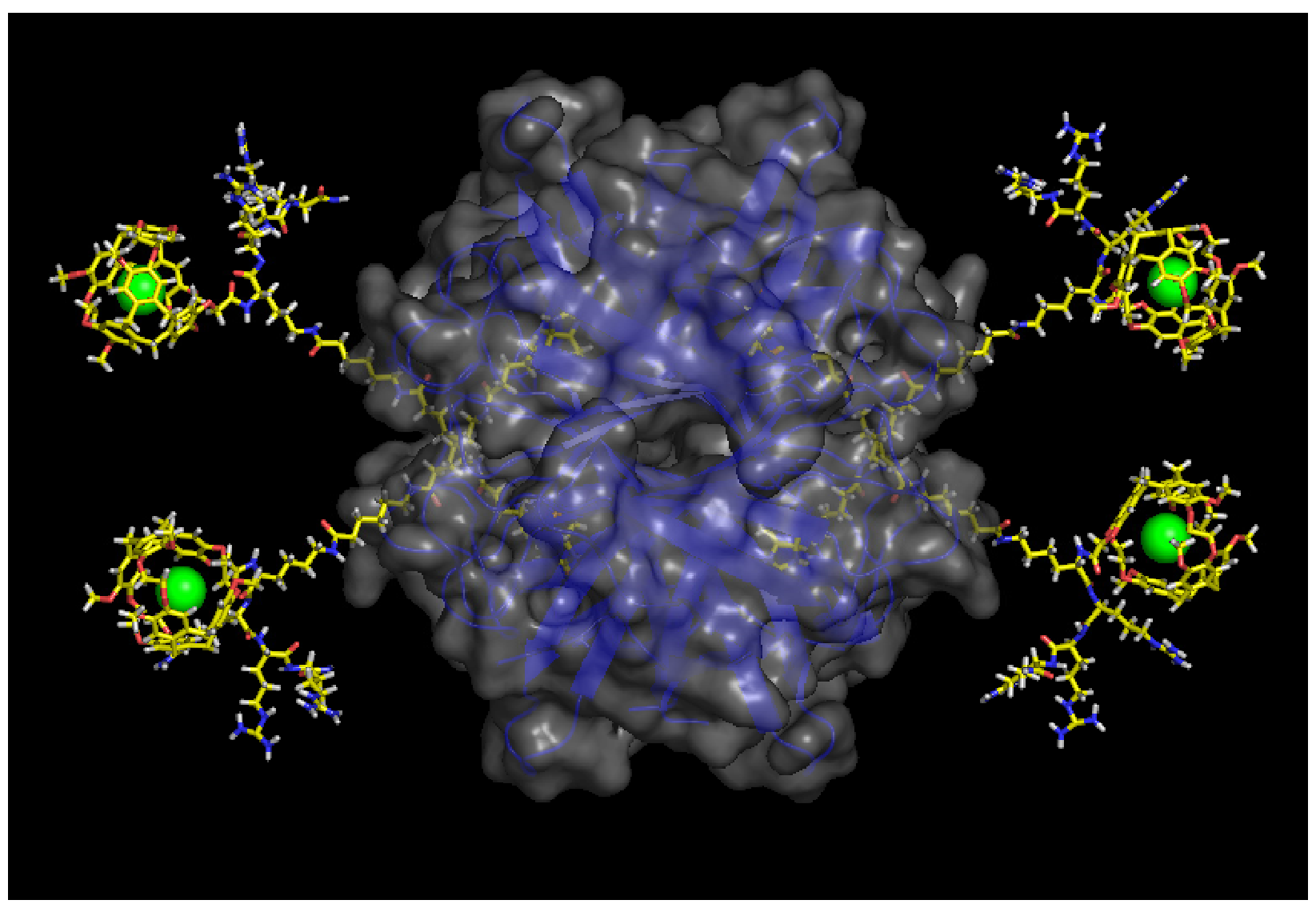




\section{Optimization of Xenon Biosensors for Detection of Protein Interactions}

Thomas J. Lowery, Sandra Garcia, Lana Chavez, E. Janette Ruiz, Tom Wu, Thierry Brotin, Jean-Pierre Dutasta, David S. King, Peter G. Schultz, Alex Pines, David E. Wemmer.

Department of Chemistry, Department of Molecular and Cell Biology and Howard Hughes Medical Institute, University of California at Berkeley Berkeley, CA 94720 (USA); Physical Biosciences and Material Sciences Division, Lawrence Berkeley National Laboratory, 1 Cyclotron Road, Berkeley, CA 94720 (USA);

Department of Chemistry and The Skaggs Institute for Chemical Biology, The Scripps Research Institute, 10550 North Torrey Pines Road, La Jolla, California 92037 (USA); Ecole Normale Superieure de Lyon, Stereochimie et Interactions Moleculaires, UMR 5532 CNRS/ENS-Lyon, 46 Allee d'Italie, 69364 Lyon 07, France.

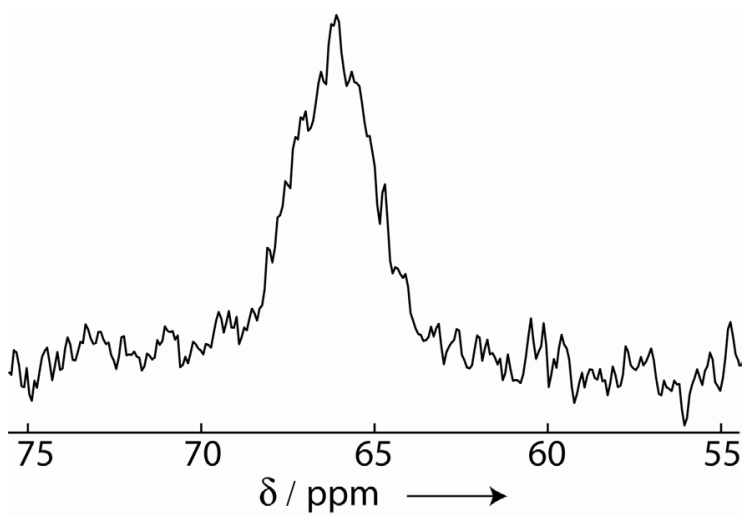

Figure s1. Spectrum of construct 1 in the presence of excess avidin obtained with the bubble-mode apparatus. The single peak is at $66.2 \mathrm{ppm}$, has a linewidth of $200 \mathrm{~Hz}$, and was collected at $20^{\circ} \mathrm{C}$ with 32 scans. 


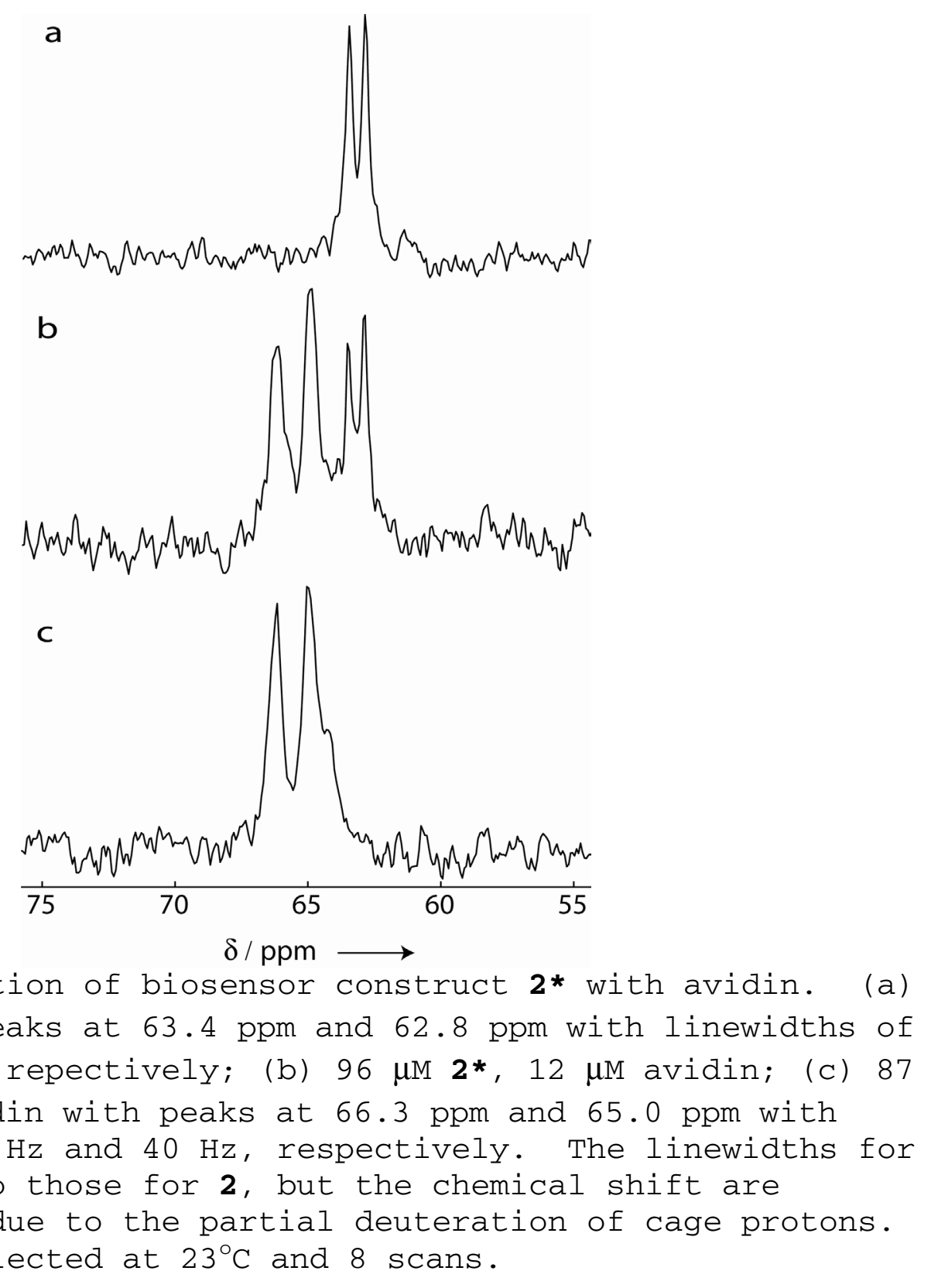




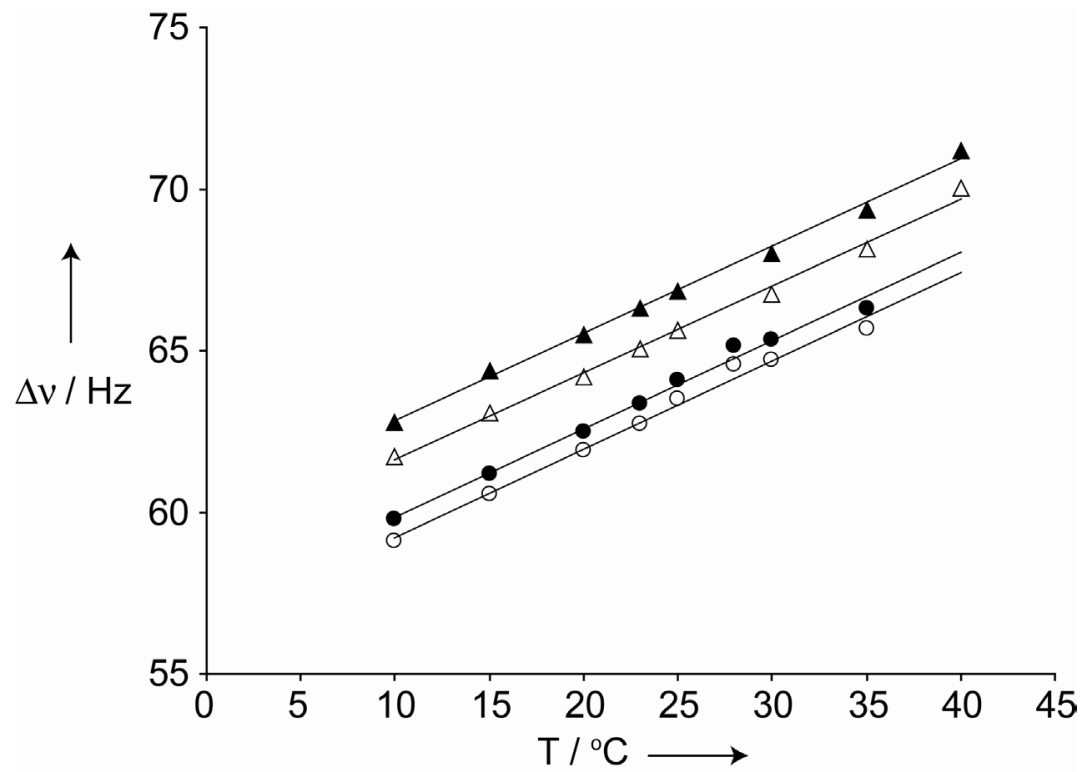

Figure s3. The change in chemical shift with temperature for both diastereomers of avidin-free (circles) and avidin-bound (triangles) construct 2*. The difference in chemical shift between the diastereomers remains constant with temperature at 0.6 ppm for avidin-free and 1.2 for avidin-bound. The temperature dependence of the chemical shift, or slope of the lines, is $0.27 \mathrm{ppm} /{ }^{\circ} \mathrm{C}$ for both forms of construct $\mathbf{2}^{*}$. The temperature dependence of xenon dissolved in solution was 0.04 $\mathrm{ppm} /{ }^{\circ} \mathrm{C}$. All spectra were referenced to the gas peak. This temperature dependence is the same as that previously observed for cryptophane-encapsulated xenon dissolved in tetrachloroethane. 

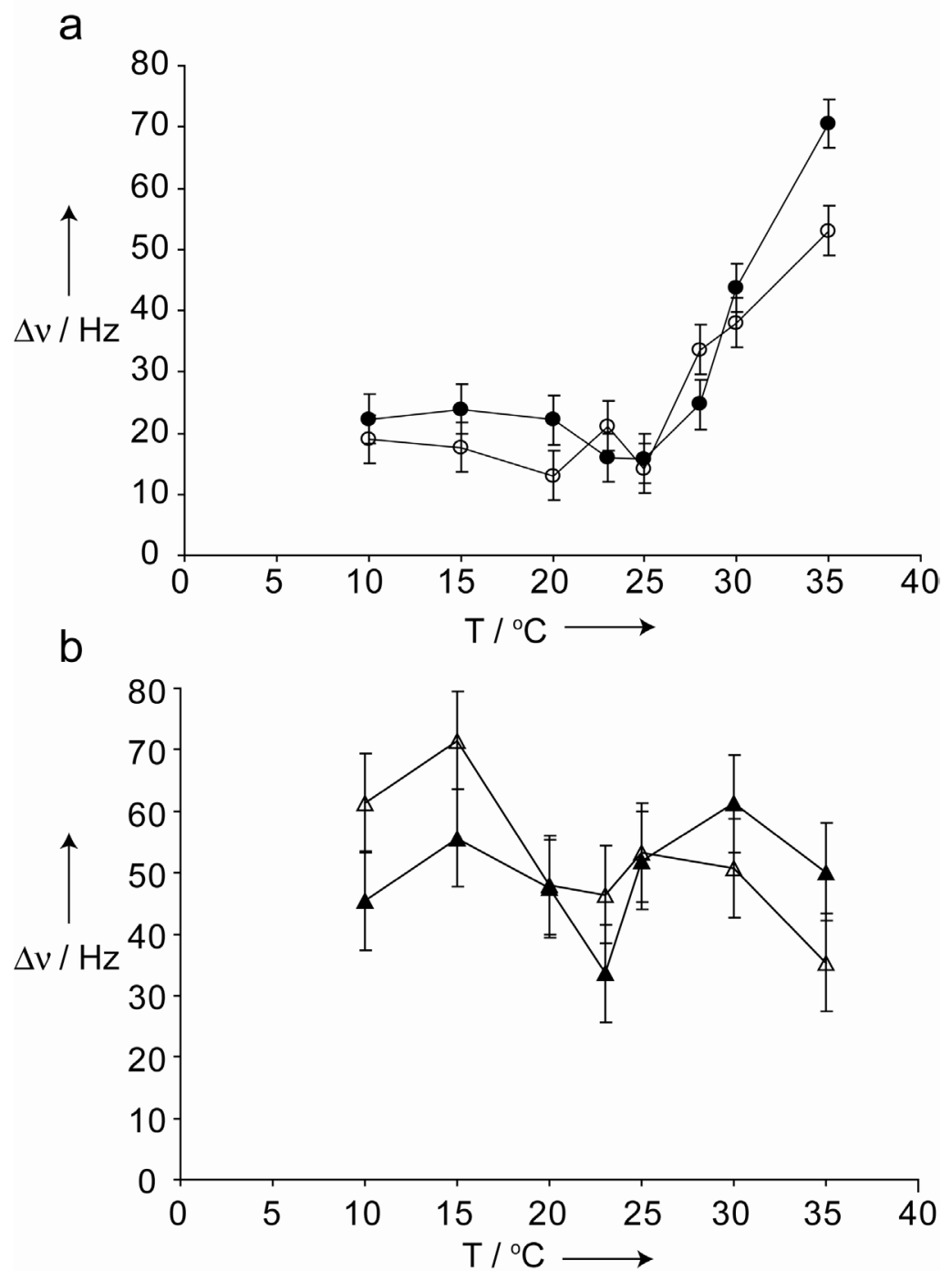

Figure s4. Temperature dependence of the linewidth for both diastereomers of the avidin-free (a) and avidin-bound (b) forms of construct 2*. Protein-free biosensor linewidth is dominated by exchange above $25^{\circ} \mathrm{C}$, but protein-bound linewidth is relatively independent of temperature. Solution linewidth for all samples were between 10 and $20 \mathrm{~Hz}$. The error in linewidth measurements for the avidin-bound form was higher due to lower signal to noise and the small, upfield peak that appears at higher temperatures (Figure 6). 


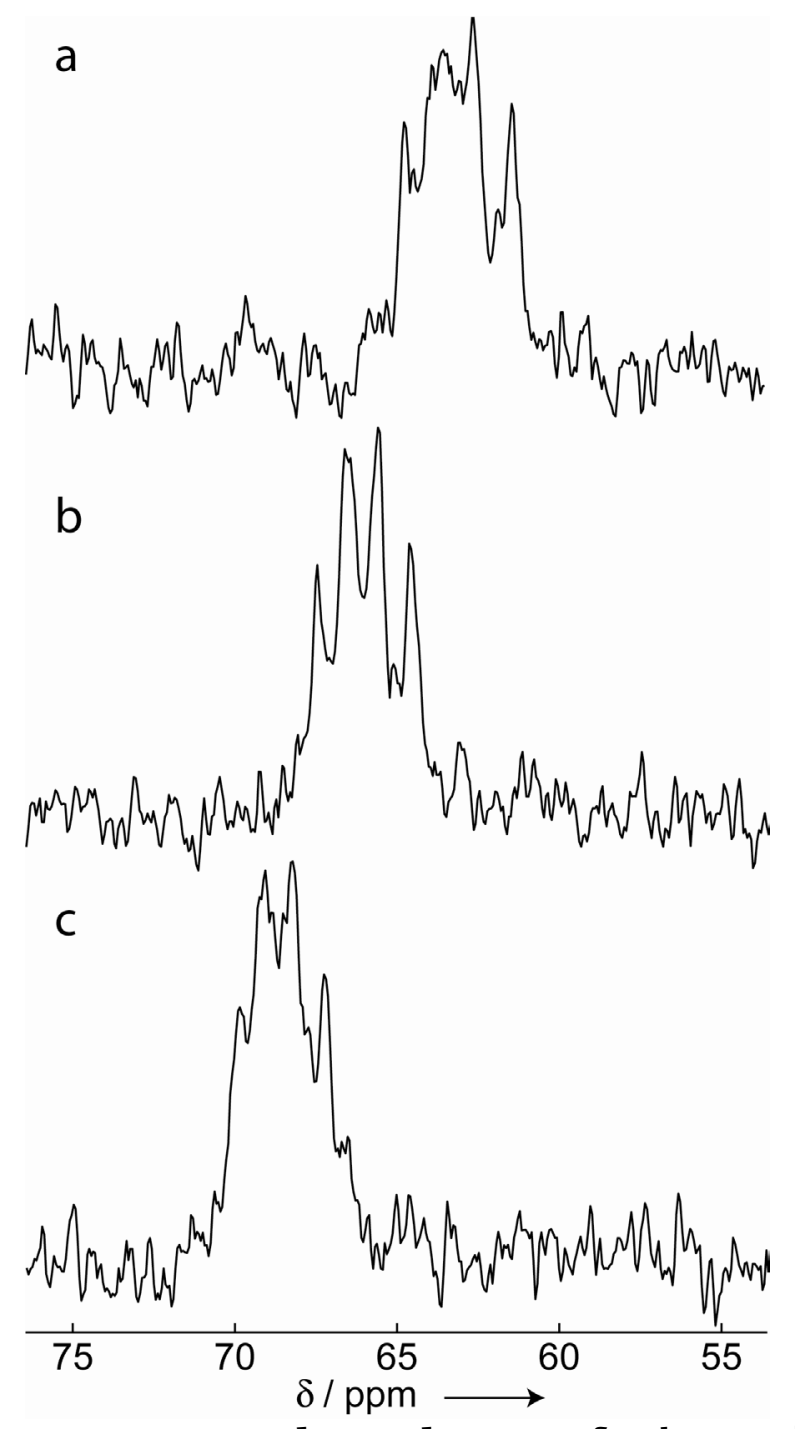

Figure s5. The temperature dependence of the avidin-bound form of construct 3 . Spectra for three different temperatures are shown, $13^{\circ} \mathrm{C}(\mathrm{a}), 23^{\circ} \mathrm{C}(\mathrm{b})$, and $33^{\circ} \mathrm{C}(\mathrm{c})$. At $23^{\circ} \mathrm{C}$ four peaks are apparent, at $67.4 \mathrm{ppm}, 66.5 \mathrm{ppm}, 65.6 \mathrm{ppm}$, and $64.5 \mathrm{ppm}$ with approximate linewidths of $50 \mathrm{~Hz}$ each. These lines broaden when the temperature is increased or decreased by $10^{\circ} \mathrm{C}$, indicating that two mechanisms of different temperature dependence contribute to linewidth of the protein-bound form of construct 3. Spectra were collected with 16 scans. 